ORIGINAL ARTICLE

\title{
Early Return to Sports to Continue the Season after Anterior Cruciate Ligament Injury Is Not Recommended for Student Athletes
}

\author{
Kohei Iio, MD a Yuka Kimura, MD a Eiji Sasaki, MD a Shizuka Sasaki, MD a Yuji Yamamoto, MD ${ }^{a}$ \\ Eiichi Tsuda, MD ${ }^{b}$ and Yasuyuki Ishibashi, MD ${ }^{\text {a }}$
}

\begin{abstract}
Objective: The objectives of this study were to investigate whether student athletes with anterior cruciate ligament (ACL) injuries who returned to sports (RTS) without reconstruction could continue their sporting activities until the end of the season and whether there was an increase in secondary damage associated with knee instability. Methods: Altogether, 288 skeletally mature patients aged $<25$ years with new-onset isolated primary ACL injuries were included. Of these, 20 student athletes continued playing sports without $\mathrm{ACL}$ reconstruction to try to finish the season and were classified as the early return to sports (ERS) group; the remaining 268 patients, who immediately quit sports and underwent surgery, were classified as the non-ERS group. Knee symptoms and sporting performance for the rest of the season were assessed for the ERS group. The presence of secondary damage, e.g., meniscus injuries and chondral lesions, associated with instability were compared between the two groups. Results: Fourteen ERS-group athletes (70\%) indicated that their knees had given way during sporting activities, and seven athletes $(35 \%)$ were unable to complete the season. In the ERS group, the mean self-estimated performance level after injury was $3.8 \pm 2.5$ (numeric rating scale $0-10$ ). Despite the RTS period being relatively short, medial meniscus tears $(\mathrm{P}<0.001)$ significantly increased in the ERS group, and three patients experienced locking of the medial meniscus and required immediate surgery. Conclusions: Although ERS without reconstruction to complete the season may be a reasonable strategy for ACL injury, patients' self-estimated performance level was low and meniscal and cartilage injury rates significantly increased.
\end{abstract}

Key Words: cartilage injury; coper; meniscus tear; reconstruction

\section{INTRODUCTION}

Anterior cruciate ligament (ACL) injury is a relatively common knee injury, particularly among young student athletes. ${ }^{1)}$ Because the ACL is one of the most important knee stabilizers, it is difficult for most athletes to participate in pivoting sports without ACL reconstruction (ACLR). Multiple studies have reported that delayed reconstruction after ACL injury increases meniscus and cartilage injury rates. ${ }^{2-10)}$ Furthermore, delayed ACLR is considered a risk factor for subsequent meniscal surgery. ${ }^{11)}$ Early ACLR prevents future meniscus tears and cartilage injuries and may reduce consequent osteoarthritis. ${ }^{12,13)}$ Therefore, the standard treatment for ACL injury is reconstruction in conjunction with a recommendation to temporarily suspend sports activity until after ACLR. ${ }^{14)}$ However, a few athletes, commonly referred to as "copers", ${ }^{15)}$ reportedly resume their prior levels of activity without dynamic instability after ACL rupture.

ACLR has several disadvantages, including graft site morbidity, long post-surgical rehabilitation period, and high

Received: August 2, 2021, Accepted: October 20, 2021, Published online: November 26, 2021

${ }^{a}$ Department of Orthopaedic Surgery, Hirosaki University Graduate School of Medicine, Hirosaki, Japan

${ }^{b}$ Department of Rehabilitation Medicine, Hirosaki University Graduate School of Medicine, Hirosaki, Japan

Correspondence: Yasuyuki Ishibashi, MD, Department of Orthopaedic Surgery, Hirosaki University Graduate School of Medicine, 5

Zaifu-cho, Hirosaki, Aomori 036-8562, Japan, E-mail: yasuyuki@hirosaki-u.ac.jp

Copyright (C) 2021 The Japanese Association of Rehabilitation Medicine

This is an open-access article distributed under the terms of the Creative Commons Attribution Non-Commercial No

Derivatives (CC BY-NC-ND) 4.0 License. http://creativecommons.org/licenses/by-nc-nd/4.0/ 
repeat injury rate. ${ }^{16)}$ Returning to sports too early involves an increased risk of repeat injury; a recent study has recommended delaying returning to sport for at least 9 months after ACLR. ${ }^{17)}$ Although careful management is recommended after ACLR, a recent systemic review reported that $63.4 \%$ of athletes returned to pre-injury level of sports, and the average time to return to sport (RTS) after reconstruction surgery was 17.2 months. ${ }^{18)}$ Because RTS is difficult within the same season after ACLR, athletes, especially student athletes, may wish to continue playing until the end of the season prior to surgery. ${ }^{19)}$ It remains unclear how these student athletes achieve successful RTS without ACLR and to what degree secondary injury could occur during the short remaining season. There have been several reports demonstrating the efficacy of conservative therapy for ACL injuries. ${ }^{20,21)}$ Moreover, in some cases, surgeons may consider granting permission to continue sporting activities to student athletes who are eager to RTS until the end of the season immediately after ACL injury, despite the patient knowing the risks involved.

The objectives of this study were to investigate whether student athletes who RTS without ACLR were able to continue their sporting activities until the end of the season and whether the rate of secondary damage associated with knee instability increased during this period. We hypothesized that, without ACLR, student athletes would not be able to achieve RTS at a satisfactory level and would suffer a higher rate of secondary injury.

\section{METHODS}

\section{Patients}

This retrospective study was approved by the Ethics Committee of Hirosaki University (\#2011-251), and all patients provided written informed consent. Between January 2013 and December 2018, 658 patients underwent ACLR at our institution. The inclusion criteria for the current study were student athletes, age $<25$ years, and a history of arthroscopic primary ACLR; consequently, 414 patients were included. The exclusion criteria were as follows: multiple knee ligament injury other than ACL injury combined with grade 1 medial collateral ligament injury $(n=13)$; revision ACL surgery $(n=90)$; history of knee surgery and combined surgery, such as high tibial osteotomy or medial patellofemoral ligament reconstruction $(n=4)$; patients with open physis $(n=5)$; and RTS without diagnosis or delayed diagnosis of ACL injury and unclear injury date (n=14) (Fig. 1).

In total, 288 patients (183 female and 105 male) were in- cluded in this study, with a mean age of $17.6 \pm 2.8$ years. Although all patients were advised to stop sporting activities and undergo ACLR, some desired to return to competitive sports until the end of the season without undergoing surgery. Although we comprehensively explained the possibility of the knee "giving way" and secondary injury resulting from knee instability, some athletes still decided to RTS to finish the season. These athletes made up the early RTS without surgery (ERS) group $(n=20)$. Those who immediately quit sports and underwent immediate or elective ACLR were classified as the non-ERS group $(n=268)$ (Fig. 1).

All patients in the ERS group wore an ACL knee brace and underwent athletic rehabilitation. The rehabilitation program was performed under the supervision of a physical therapist. Physical therapy was performed in seven steps: range of motion exercises, isometric muscle-strengthening exercises, full weight-bearing and closed kinetic chain exercises, running, open kinetic chain exercises, jump-landing training, and sports-specific training. However, athletes in the ERS group decided on their own whether to participate in sporting activities, as the remaining time in the season was limited.

\section{Status and Satisfaction Relating to Early Re- turn to Sports}

The questionnaire survey items for the ERS group included the following: the time between injury and RTS, whether sporting activities were continued until the end of the season, the period for which sports activity was continued (from RTS to the end of the season or quitting sports), experience of knee giving way, and catching or locking episodes during sports activity. ${ }^{15)}$ A numerical rating scale (NRS) was used to assess the self-estimated satisfaction score with the decision to RTS without surgery (10: completely satisfied, 0 : completely dissatisfied), and the sports performance level (10: same as pre-injury level, 0 : impossible to participate in the game).

\section{Evaluation of Meniscus Tears and Cartilage In- juries}

Initial magnetic resonance imaging (MRI) results after ACL injury were analyzed by radiologists who were unaware of the treatment options chosen by the patients. Medial meniscus (MM) and lateral meniscus (LM) injuries found on the initial MRI were defined as radiological meniscus injuries and were compared between the ERS and non-ERS groups. All arthroscopic ACLRs were performed or directly supervised by the senior author (Y.I.). Meniscus injuries 


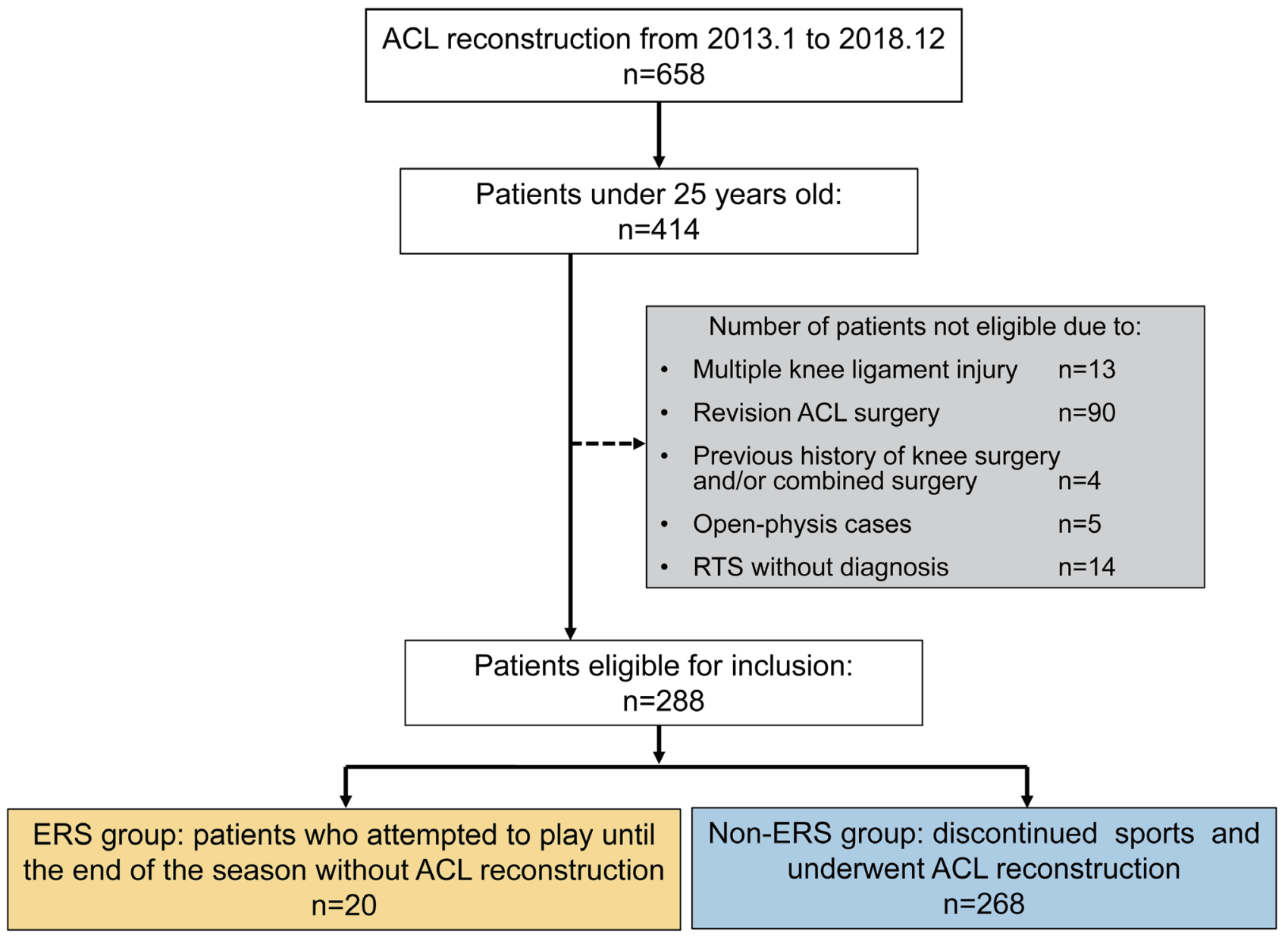

Fig. 1. Participant selection process. Of the 414 subjects aged less than 25 years who underwent anterior cruciate ligament reconstruction, 288 were included in this study. Of these, 20 patients decided to return to sport to try to complete the season.

found during ACLR were defined as definitive meniscal injuries and were compared between the groups. Meniscal injuries included both complete and partial thickness tears as well as ramp lesions. Articular cartilage injuries were assessed by arthroscopy according to the International Cartilage Repair Society (ICRS) system. The locations of the lesions were classified as follows: patellar, trochlear, medial femoral condyle, medial tibial plateau, lateral femoral condyle, or lateral tibial plateau.

\section{Statistical Analysis}

To achieve $80 \%$ statistical power with an alpha of 0.05 , power analysis indicated that a minimum of 12 patients in the ERS group and 157 patients in the non-ERS group would be required to detect any differences in the prevalence of concomitant injuries using the chi-square test. Post hoc power analysis showed that the actual power of the current analysis was 0.953 , with an alpha of 0.05 .
Demographic data are shown as means and standard deviations. According to the Shapiro-Wilk test, none of the parameters were normally distributed. Consequently, age, body mass index, time between injury and MRI, time between injury and ACLR, and Tegner activity scale scores were compared between the ERS and non-ERS groups using the Mann-Whitney U test. Additionally, the prevalences of radiographic meniscus injury, definitive meniscus injury, and definitive cartilage injury were compared using the chi-square test or Fisher's exact test. Data input and analyses were performed using SPSS version 27.0 (SPSS Inc., Chicago, IL, USA). Statistical significance was set at $\mathrm{P}<0.05$.

\section{RESULTS}

\section{Demographic Characteristics}

The ERS group comprised 14 female and 6 male patients (17.0 \pm 2.8 years), and the non-ERS group comprised 169 
Table 1. Patient demographics

\begin{tabular}{lccc}
\hline & ERS group & Non-ERS group & P-value \\
& $\mathrm{n}=20$ & $17.7 \pm 2.8$ & 0.310 \\
\hline Age & $17.0 \pm 2.8$ & $169 / 99$ & 0.534 \\
Female/male & $14 / 6$ & $23.7 \pm 3.8$ & 0.542 \\
BMI & $23.9 \pm 3.0$ & $7.7 \pm 14.2$ & 0.419 \\
Period $^{\text {a }}$ to MRI (days) & $8.1 \pm 9.7$ & $47.1 \pm 37.7$ & $<0.001$ \\
Period $^{b}$ to ACLR (days) & $162.8 \pm 87.6$ & $6.9 \pm 1.3$ & 0.803 \\
Tegner activity score & $7.0 \pm 0.6$ & & \\
\hline
\end{tabular}

ERS, early return to sports, BMI, body mass index. MRI, magnetic resonance imaging, ACLR, anterior cruciate ligament reconstruction.

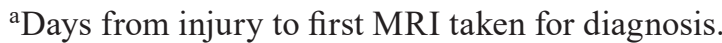

bDays from injury to ACLR.

female and 99 male patients $(17.7 \pm 2.8$ years $)$. All athletes in the ERS group participated in competitive sports at the prefectural level or above. In contrast, most of the athletes in the non-ERS group competed at the prefectural level, but some were active only in recreational sports. There was no significant difference in the Tegner activity scores between the two groups. Moreover, there was no significant difference between the two groups in the number of days between injury and diagnostic MRI (Table 1). The period between injury and ACLR was significantly longer in the ERS group $(162.8 \pm 87.6$ days $)$ than in the non-ERS group $(47.1 \pm 37.7$ days, $\mathrm{P}<0.001)$. The most common activity when acquiring ACL injury was playing basketball (Table 2).

\section{Status and Satisfaction in Early Return to Sports}

The average period until RTS after injury in the ERS group was $24.5 \pm 23.4$ (9-112) days (Table 3). Although 13 of the 20 ERS athletes continued their sporting activities until the end of the season, the remaining 7 athletes quit sports and underwent ACLR because of knee instability or MM locking. The mean period for which sports activity was continued was $79.0 \pm 52.9$ (14-210) days. Fourteen athletes (70\%) experienced their knee "giving way" during sports activity, and seven athletes $(35 \%)$ experienced catching or locking episodes. Of these, three athletes experienced MM locking; consequently, immediate MM repairs combined with ACLR were performed. The average satisfaction score was $6.5 \pm 2.9$ (range 1-10), and the average performance level after injury was $3.8 \pm 2.5$ (range $2-8$ ).

\section{Evaluation of Meniscus Tears and Cartilage In- juries}

The prevalence of radiological MM injury, as detected on initial MRI, was $25.0 \%$ and $23.1 \%$ in the ERS and non-ERS groups, respectively ( $\mathrm{P}=0.789)$ (Table 4). The prevalence of radiographic LM injury was $35.0 \%$ and $46.3 \%(\mathrm{P}=0.329)$, respectively. The prevalence of definitive MM in the ERS and non-ERS groups was $65.0 \%$ and $26.1 \%$, respectively, whereas for definitive LM injuries, the prevalences were $40.0 \%$ and $57.8 \%$, respectively. The prevalence of definitive MM injury in the ERS group was significantly higher than that in the non-ERS group $(\mathrm{P}<0.001)$. Articular cartilage injury was found in $30 \%$ and $15.3 \%$ of the patients in the ERS and non-ERS groups, respectively $(\mathrm{P}=0.086)$, and no grade IV lesions were detected. Most cartilage lesions were located on the medial femoral condyle in both groups, and the prevalence of medial femoral condyle injury in the ERS group was significantly higher than that in the non-ERS group $(\mathrm{P}=0.021)$.

\section{DISCUSSION}

In the present study, the primary finding was that the performance level of young ACL-injured athletes who continued playing for the rest of the season without ACLR was relatively low. Although the athletes in the RTS group did not regret their decision, their performance level was significantly lower $(3.8 \pm 2.5)$ than they expected, and $35 \%$ of the RTS athletes could not continue their sporting activities until the end of the season. Despite the relatively short periods that RTS athletes were engaged in sporting activities, MM tears and cartilage lesions of the medial femoral condyle significantly increased in the ERS group. Furthermore, MM locking occurred in three patients (15\%) and resulted in the discontinuation of sports activity and immediate surgery.

In the current study, $6.9 \%$ of patients under 25 years of age attempted to return to competitive sports without ACLR. The 
Table 2. Cause of injury

\begin{tabular}{lcc}
\hline Sports activity & $\begin{array}{c}\text { ERS group } \\
\mathrm{n}=20\end{array}$ & $\begin{array}{c}\text { Non-ERS group } \\
\mathrm{n}=268\end{array}$ \\
\hline Basketball & $10(50 \%)$ & $104(38.8 \%)$ \\
Skiing & $2(10 \%)$ & $36(13.4 \%)$ \\
Soccer & $3(15 \%)$ & $27(10.1 \%)$ \\
Volleyball & $1(5 \%)$ & $28(10.4 \%)$ \\
Judo & $1(5 \%)$ & $17(6.3 \%)$ \\
Gymnastics & $1(5 \%)$ & $13(4.9 \%)$ \\
Rugby, American football & $0(0 \%)$ & $11(4.1 \%)$ \\
Track and field & $1(5 \%)$ & $8(3.0 \%)$ \\
Badminton & $0(0 \%)$ & $8(3.0 \%)$ \\
Baseball & $1(5 \%)$ & $5(1.9 \%)$ \\
Other sports $^{\mathrm{a}}$ & $0(0 \%)$ & $6(2.2 \%)$ \\
Other trauma $^{\mathrm{b}}$ & $0(0 \%)$ & $5(1.9 \%)$ \\
\hline
\end{tabular}

${ }^{a}$ Handball, tennis, or dance.

${ }^{\mathrm{b}}$ Falls or traffic accidents.

Table 3. Status and satisfaction in early-return-to-sports group

\begin{tabular}{lc}
\hline & $\begin{array}{c}\text { ERS group } \\
\mathrm{n}=20\end{array}$ \\
\hline RTS after injury (days) & $24.5 \pm 23.4$ \\
Sports continuation to end of season & $65 \%(13 / 20)$ \\
Sport continuation period (days) & $79.0 \pm 52.9$ \\
Awareness of knee giving way & $70 \%(14 / 20)$ \\
Awareness of knee catching or locking & $35 \%(7 / 20)$ \\
Sports performance level & $3.8 \pm 2.5(2-8)$ \\
Satisfaction score & $6.5 \pm 2.9(1-10)$ \\
\hline
\end{tabular}

satisfaction scale score of 6.5 for the decision was low, even though the average time from injury to RTS was much shorter than that for the usual protocol after ACLR. During sporting activities, most players experienced pain, "giving way", and catching of the injured knee. Only six members (30\%) of the RTS group did not experience their knee "giving way" during a game, and self-estimated performance levels were less than half of the pre-injury levels. Furthermore, two athletes who did not experience their knee "giving way" experienced MM locking and discontinued sporting activities during the season. For athletes returning to sporting activities after conservative treatment of ACL injury, Takata reported a conscious performance score of $58.4 \%$, and $90.5 \%$ of players experienced their knee "giving way" during participation in sport. ${ }^{19)}$ As suggested in that study, conservative treatment of athletes with ACL injuries should be carefully assessed taking these findings into account. Baez et al. reported that injury-related fear was associated with RTS and physical activity levels after ACLR. ${ }^{22)}$ Hartigan et al. reported that kinesiophobia before surgery was lower in potential copers than in non-copers, but kinesiophobia before surgery was higher than that after surgery in both groups. ${ }^{23)}$ Although we did not investigate psychological factors, psychological evaluations should be conducted in future studies.

The "rule of thirds" implies that one-third of patients with an ACL injury compensate well without ACLR (copers), onethird adapt by modifying their activities (adapters), and the remaining one-third require ACLR (non-copers). ${ }^{24)}$ Thoma et al. reported that after 6 months of progressive neuromuscular and strength training, the proportion of potential copers increased. ${ }^{15)}$ Although progressive rehabilitation might improve performance levels, patients in the ERS group did not have enough time for rehabilitation to take effect within the same season. A longer period of progressive rehabilita- 
Table 4. The prevalence of concomitant injuries discovered on MRI or during surgery

\begin{tabular}{lccc}
\hline & $\begin{array}{c}\text { ERS group } \\
\mathrm{n}=20\end{array}$ & $\begin{array}{c}\text { Non-ERS group } \\
\mathrm{n}=268\end{array}$ & P-value \\
\hline Radiological meniscus injury & & & \\
Medial meniscus & $5(25.0 \%)$ & $62(23.1 \%)$ & 0.789 \\
Lateral meniscus & $7(35.0 \%)$ & $124(46.3 \%)$ & 0.329 \\
\hline Definitive meniscus injury & & & \\
Medial meniscus & $13(65.0 \%)$ & $70(26.1 \%)$ & $<0.001$ \\
Lateral meniscus & $8(40.0 \%)$ & $155(57.8 \%)$ & 0.121 \\
\hline Definitive cartilage injury & & & \\
Total number of patients & $6(30.0 \%)$ & $41(15.3 \%)$ & 0.086 \\
MFC & $6(30.0 \%)$ & $32(11.9 \%)$ & 0.021 \\
MTP & $0(0.0 \%)$ & $3(1.1 \%)$ & 1.000 \\
LFC & $1(5.0 \%)$ & $5(1.9 \%)$ & 0.353 \\
LTP & $0(0.0 \%)$ & $1(0.4 \%)$ & 1.000 \\
Patella & $0(0.0 \%)$ & $7(2.6 \%)$ & 1.000 \\
Trochlea & $0(0.0 \%)$ & $0(0.0 \%)$ & 1.000 \\
\hline
\end{tabular}

MFC, medial femoral condyle, MTP, medial tibial plateau, LFC, lateral femoral condyle, LTP, lateral tibial plateau.

tion might improve the performance and satisfaction scale scores reported in the current study.

Several previous studies reported that delaying ACLR increases MM tears and cartilage lesions, but does not increase LM tears. ${ }^{2,3,5.9)}$ Although our results indicated similar outcomes in student athletes, more severe damage was detected because of continued engagement in competitive sports. This result was also consistent with a report by Anderson et al. that sporting activity and experience of knees giving way more than twice were risk factors for secondary injuries. ${ }^{2)}$ At our institution, we routinely endeavor to conduct ACLR early; the mean time to ACLR from injury was 47.1 days in the non-ERS group. Therefore, rates of medial meniscus tears and cartilage lesions were relatively low compared with those reported in previous studies. ${ }^{2-10)}$ Because early ACLR might reduce secondary $\mathrm{MM}$ and cartilage injury, clinical guidelines for ACL injuries recommend ACLR within 3-6 months of injury. ${ }^{12)}$ Moreover, early surgical intervention also reduces the risk of subsequent meniscal surgery after ACLR. ${ }^{11)}$

LM tears are predominantly observed in acute ACL injury. ${ }^{25,26)}$ In the current study, LM tears did not increase in the ERS group, compared with the non-ERS group, similar to the findings of previous studies. ${ }^{2,3,5,9)}$ Shelbourne and Heinrich reported good long-term outcomes of ACLR without LM repair or resection. ${ }^{27)}$ However, recent biomechanical and clinical studies have demonstrated the importance of LM repair in reducing anterolateral instability after ACLR. ${ }^{28-30)}$
Therefore, unstable LM tears should be repaired to improve ACLR outcomes. Everhart et al. reported that the risk of high-grade medial chondral damage increased if the period between injury and ACLR was greater than 5 months. ${ }^{3)}$ In the current study, the majority of cartilage damage occurred in the medial femoral condyle in both the ERS and non-ERS groups, and cartilage damage was more frequently detected in the ERS group than in the non-ERS group. Typical MRI findings for ACL injuries include bone marrow edema on the lateral femoral condyle. Just as for meniscus injuries, lateral femoral condyle lesions sometimes occur upon injury, whereas medial condyle injury may develop gradually after injury because of instability. However, Sugiu et al. reported that cartilage lesions had increased on second-look arthroscopy after successful ACLR. ${ }^{31)}$ Their findings suggested that cartilage degeneration occurs progressively after ACLR. Further long-term follow-up with X-ray investigations and MRI will be necessary to evaluate and compare the progression of cartilage injury in the ERS and non-ERS groups.

The current study has several limitations that should be considered. First, the number of participants in the ERS group was relatively small, and the sample was not randomly selected. To reduce secondary intra-articular injuries, our primary therapeutic strategy for ACL-injured patients is to reconstruct the ACL as early as possible. As a result, patients in the ERS group were limited to athletes who were eager to RTS. Second, secondary meniscal injury was determined using two different methods: MRI and arthroscopic findings 
with probing. The MRI scan may have missed minor partialthickness tears. Third, the current data were retrospectively collected, and all subjects underwent reconstruction surgery, likely excluding some coper subjects. Fourth, patients whose early RTS was successful without requiring future surgery are absent. Another limitation is that the sports performance level was evaluated using an NRS. We defined 10 as the same as the pre-injury level, and 0 as being impossible to participate in the game. But 1 to 9 were not defined and were completely subjective scores registered by the players. It would have been difficult to define performance levels more rigorously because the patients were involved in different sports. Finally, this study did not compare clinical results after ACLR. Despite these limitations, the current data are clinically relevant and indicate that healthcare providers should undertake careful management of young ACL-injured athletes who are eager to RTS for the rest of the season, because their sporting performance may be low and they may not be satisfied with their decision to RTS.

\section{CONCLUSION}

Although ERS in the same season as injury without ACLR appears to be a feasible strategy for ACL injury, patients' self-estimated performance levels were low, and meniscal and cartilage injuries significantly increased. Physicians should clearly explain to patients that, in ERS, they will be unlikely to achieve their original sporting level and that ERS has a high complication rate.

\section{CONFLICTS OF INTEREST}

The authors declare that they have no competing interests.

\section{REFERENCES}

1. Secrist ES, Frederick RW, Tjoumakaris FP, Stache SA, Hammoud S, Freedman KB: A Comparison of operative and nonoperative treatment of anterior cruciate ligament injuries. JBJS Rev 2016;4:11. DOI:10.2106/ JBJS.RVW.15.00115, PMID:27922986

2. Anderson AF, Anderson CN: Correlation of meniscal and articular cartilage injuries in children and adolescents with timing of anterior cruciate ligament reconstruction. Am J Sports Med 2015;43:275-281. DOI:10.1177/0363546514559912, PMID:25497145
3. Everhart JS, Kirven JC, Abouljoud MM, DiBartola AC, Kaeding CC, Flanigan DC: Effect of delayed primary anterior cruciate ligament reconstruction on medial compartment cartilage and meniscal health. Am J Sports Med 2019;47:1816-1824. DOI:10.1177/0363546519849695, PMID:31125273

4. Granan LP, Bahr R, Lie SA, Engebretsen L: Timing of anterior cruciate ligament reconstructive surgery and risk of cartilage lesions and meniscal tears: a cohort study based on the Norwegian National Knee Ligament Registry. Am J Sports Med 2009;37:955-961. DOI:10.1177/0363546508330136, PMID:19251674

5. Kluczynski MA, Marzo JM, Bisson LJ: Factors associated with meniscal tears and chondral lesions in patients undergoing anterior cruciate ligament reconstruction: a prospective study. Am J Sports Med 2013;41:2759-2765. DOI:10.1177/0363546513503448, PMID:24044906

6. Krutsch W, Zellner J, Baumann F, Pfeifer C, Nerlich M, Angele P: Timing of anterior cruciate ligament reconstruction within the first year after trauma and its influence on treatment of cartilage and meniscus pathology. Knee Surg Sports Traumatol Arthrosc 2017;25:418-425. DOI:10.1007/s00167-015-3830-2, PMID:26475153

7. Mehl J, Otto A, Baldino JB, Achtnich A, Akoto $\mathrm{R}$, Imhoff AB, Scheffler S, Petersen W: The ACLdeficient knee and the prevalence of meniscus and cartilage lesions: a systematic review and meta-analysis (CRD42017076897). Arch Orthop Trauma Surg 2019;139:819-841. DOI:10.1007/s00402-019-03128-4, PMID:30758661

8. Mok YR, Wong KL, Panjwani T, Chan CX, Toh SJ, Krishna L: Anterior cruciate ligament reconstruction performed within 12 months of the index injury is associated with a lower rate of medial meniscus tears. Knee Surg Sports Traumatol Arthrosc 2019;27:117-123. DOI:10.1007/s00167-018-5027-y, PMID:29978305

9. Nault ML, Ledoux L, Saad L, Grimard G, Glavas P: Meniscal and chondral injuries associated with surgical delay before anterior cruciate ligament reconstruction in adolescents. J ISAKOS Jt Disord Orthop Sports Med 2018;3:258-262. DOI:10.1136/jisakos-2018-000216 
10. Papastergiou SG, Koukoulias NE, Mikalef P, Ziogas E, Voulgaropoulos H: Meniscal tears in the ACLdeficient knee: correlation between meniscal tears and the timing of ACL reconstruction. Knee Surg Sports Traumatol Arthrosc 2007;15:1438-1444. DOI:10.1007/ s00167-007-0414-9, PMID:17899001

11. Kimura Y, Sasaki E, Yamamoto Y, Sasaki S, Tsuda E, Ishibashi Y: Incidence and risk factors of subsequent meniscal surgery after successful anterior cruciate ligament reconstruction: a retrospective study with a minimum 2-year follow-up. Am J Sports Med 2020;48:3525-3533. DOI:10.1177/0363546520967670, PMID:33125263

12. Ishibashi $Y$, Adachi N, Koga H, Kondo E, Kuroda R, Mae T, Uchio Y: Japanese Orthopaedic Association (JOA) clinical practice guidelines on the management of anterior cruciate ligament injury - secondary publication. J Orthop Sci 2020;25:6-45. DOI:10.1016/j. jos.2019.10.009, PMID:31843222

13. Sanders TL, Kremers HM, Bryan AJ, Fruth KM, Larson DR, Pareek A, Levy BA, Stuart MJ, Dahm DL, Krych AJ: Is anterior cruciate ligament reconstruction effective in preventing secondary meniscal tears and osteoarthritis? Am J Sports Med 2016;44:1699-1707. DOI:10.1177/0363546516634325, PMID:26957217

14. Hetsroni I, Marx RG: Early vs. delayed ACL reconstruction "early" anterior cruciate ligament reconstruction. In: Nakamura N, Zaffagnini S, Marx RG, Musahl $\mathrm{V}$, eds, Controversies in the technical aspects of ACL reconstruction, 1st edn. Springer, Berlin, Heidelberg, 2017. pp 19-26.

15. Thoma LM, Grindem H, Logerstedt D, Axe M, Engebretsen L, Risberg MA, Snyder-Mackler L: Coper classification early after anterior cruciate ligament rupture changes with progressive neuromuscular and strength training and is associated with 2-year success: The Delaware-Oslo ACL Cohort Study. Am J Sports Med 2019;47:807-814. DOI:10.1177/0363546519825500, PMID:30790527

16. Grindem H, Engebretsen L, Axe M, Snyder-Mackler L, Risberg MA: Activity and functional readiness, not age, are the critical factors for second anterior cruciate ligament injury - The Delaware-Oslo ACL Cohort Study. Br J Sports Med 2020;54:1099-1102. DOI:10.1136/bjsports-2019-100623, PMID:32046955
17. Grindem H, Snyder-Mackler L, Moksnes H, Engebretsen L, Risberg MA: Simple decision rules can reduce reinjury risk by $84 \%$ after ACL reconstruction: The Delaware-Oslo ACL Cohort Study. Br J Sports Med 2016;50:804-808. DOI:10.1136/bjsports-2016-096031, PMID:27162233

18. Nwachukwu BU, Adjei J, Rauck RC, Chahla J, Okoroha KR, Verma NN, Allen AA, Williams RJ III: How much do psychological factors affect lack of return to play after anterior cruciate ligament reconstruction? A systematic review. Orthop J Sports Med 2019;7:2325967119845313. DOI:10.1177/2325967119845313, PMID:31205965

19. Takata Y, Nakase J, Toratani T, Numata H, Oshima T, Kitaoka K, Tsuchiya H: Conscious performance and arthroscopic findings in athletes with anterior cruciate ligament injuries treated via conservative therapy during the competitive season. J Orthop Surg (Hong Kong) 2017;25:2309499016684751. DOI:10.1177/2309499016684751, PMID:28193143

20. Keays SL, Newcombe P, Keays AC: Nearly 90\% participation in sports activity 12 years after non-surgical management for anterior cruciate ligament injury relates to physical outcome measures. Knee Surg Sports Traumatol Arthrosc 2019;27:2511-2519. DOI:10.1007/ s00167-018-5258-y, PMID:30386997

21. Weiler R, Monte-Colombo M, Mitchell A, Haddad F: Non-operative management of a complete anterior cruciate ligament injury in an English Premier League football player with return to play in less than 8 weeks: applying common sense in the absence of evidence. Case Rep 2015;2015(apr26 1):bcr2014208012. DOI:10.1136/bcr-2014-208012, PMID:25917066

22. Baez SE, Hoch MC, Hoch JM: Psychological factors are associated with return to pre-injury levels of sport and physical activity after ACL reconstruction. Knee Surg Sports Traumatol Arthrosc 2020;28:495-501. DOI:10.1007/s00167-019-05696-9, PMID:31486916

23. Hartigan EH, Lynch AD, Logerstedt DS, Chmielewski TL, Snyder-Mackler L: Kinesiophobia after anterior cruciate ligament rupture and reconstruction: noncopers versus potential copers. J Orthop Sports Phys Ther 2013;43:821-832. DOI:10.2519/jospt.2013.4514, PMID:24175594 
24. Noyes FR, Matthews DS, Mooar PA, Grood ES: The symptomatic anterior cruciate-deficient knee. Part II: the results of rehabilitation, activity modification, and counseling on functional disability. J Bone Joint Surg Am 1983;65:163-174. DOI:10.2106/00004623198365020-00004, PMID:6822580

25. Feucht MJ, Bigdon S, Bode G, Salzmann GM, DoviAkue D, Südkamp NP, Niemeyer P: Associated tears of the lateral meniscus in anterior cruciate ligament injuries: risk factors for different tear patterns. J Orthop Surg Res 2015;10:34. DOI:10.1186/s13018-015-0184-X, PMID:25889148

26. Nikolić DK: Lateral meniscal tears and their evolution in acute injuries of the anterior cruciate ligament of the knee. Arthroscopic analysis. Knee Surg Sports Traumatol Arthrosc 1998;6:26-30. DOI:10.1007/ s001670050068, PMID:9507467

27. Shelbourne KD, Heinrich J: The long-term evaluation of lateral meniscus tears left in situ at the time of anterior cruciate ligament reconstruction. Arthroscopy 2004;20:346-351. DOI:10.1016/j.arthro.2004.01.029, PMID:15067272
28. Hoshino Y, Hiroshima Y, Miyaji N, Nagai K, Araki D, Kanzaki N, Kakutani K, Matsushita T, Kuroda R: Unrepaired lateral meniscus tears lead to remaining pivotshift in ACL-reconstructed knees. Knee Surg Sports Traumatol Arthrosc 2020;28:3504-3510. DOI:10.1007/ s00167-020-06007-3, PMID:32328696

29. Katakura M, Horie M, Watanabe T, Katagiri H, Otabe K, Ohara T, Nakamura K, Katagiri K, Ueki H, Zaffagnini S, Sekiya I, Muneta T, Koga H: Effect of meniscus repair on pivot-shift during anterior cruciate ligament reconstruction: objective evaluation using triaxial accelerometer. Knee 2019;26:124-131. DOI:10.1016/j. knee.2018.11.016, PMID:30554908

30. Shybut TB, Vega CE, Haddad J, Alexander JW, Gold JE, Noble PC, Lowe WR: Effect of lateral meniscal root tear on the stability of the anterior cruciate ligamentdeficient knee. Am J Sports Med 2015;43:905-911. DOI:10.1177/0363546514563910, PMID:25589386

31. Sugiu K, Furumatsu T, Kodama Y, Kamatsuki Y, Okazaki Y, Okazaki Y, Hiranaka T, Ozaki T: Post-traumatic articular cartilage lesions increase at second-look arthroscopy following primary anterior cruciate ligament reconstruction. Acta Med Okayama 2019;73:223-228. DOI:10.18926/AMO/56864, PMID:31235969 